\title{
The Association between Ambient Fine Particulate Matter and Oral Neoplasm among Smokers and Betel Quids Chewers
}

\author{
Mei-Sheng Ku${ }^{1}$, Pallop Siewchaisakul ${ }^{2,3}$, Amy Ming-Fang Yen², Chen-Yu Liu ${ }^{1 *}$ \\ ${ }^{1}$ Institute of Environmental and Occupational Health Science, College of Public Health, National \\ Taiwan University, Taipei, Taiwan \\ ${ }^{2}$ School of Oral Hygiene, College of Oral Medicine, Taipei Medical University, Taipei, Taiwan \\ ${ }^{3}$ Faculty of Public Health, Chiang Mai University, Thailand
}

\section{ABSTRACT}

The association between fine particulate matter $<2.5 \mu \mathrm{m}\left(\mathrm{PM}_{2.5}\right)$ and oral neoplasm has barely been addressed. The purpose of this study is to elucidate the association between $\mathrm{PM}_{2.5}$ and oral neoplasm, including oral potentially malignant disorder (OPMD) and oral cancer (OC), taking into account the geographical heterogeneity. Data for analysis were derived from nationwide OC screening program, targeting Taiwanese cigarette smokers and/or betel quid chewers, and the Taiwan Air Quality Monitoring Network between 2006 and 2016. Totally 3,864,045 smokers and/or betel quids chewers were enrolled in this study. Among them, 154,030 OPMD cases and 23,286 oral cancers were found during the study period. Information on age, gender, living area, personal oral habits, and monthly $\mathrm{PM}_{2.5}$ concentration in average were collected. We used the Bayesian random-effect logistic regression model to assess the association between $\mathrm{PM}_{2.5}$ and OPMD/OC. After adjusting for sex, age, and behavior of betel quid chewing and cigarette smoking, we found that subjects from areas of higher levels of $\mathrm{PM}_{2.5}\left(\geq 35 \mu \mathrm{g} \mathrm{m}^{-3}\right)$ had an increased risk of OPMD/OC and OC by $11 \%(a R R=1.11 ; 95 \% \mathrm{Cl}: 1.09-1.13)$ and $55 \%(a R R=1.55 ; 95 \% \mathrm{Cl}: 1.49-$ 1.60) respectively, compared to those from areas of lower $\mathrm{PM}_{2.5}\left(<35 \mu \mathrm{g} \mathrm{m}^{-3}\right)$. Such effect was further demonstrated in a concentration-dependent manner. Subjects from areas of higher $\mathrm{PM}_{2.5}$ levels were found to have greater risk of OPMD/OC in Taiwan. Future studies are warranted to investigate the effect of personal $\mathrm{PM}_{2.5}$ exposure on OPMD/OC risk.

Received: March 21, 2021

Revised: June 29, 2021

Accepted: July 23, 2021

${ }^{*}$ Corresponding Author:

chenyuliu@ntu.edu.tw

\section{Publisher:}

Taiwan Association for Aerosol Research

ISSN: $1680-8584$ print ISSN: 2071-1409 online

(c) Copyright: The Author(s). This is an open access article distributed under the terms of the Creative Commons Attribution License (CC BY 4.0), which permits unrestricted use, distribution, and reproduction in any medium, provided the original author and source are cited.
Keywords: Particulate matter, Oral cancer, Nationwide screening program, Taiwan

\section{INTRODUCTION}

It is inevitable that air pollution has become environmental burden worldwide. Among all air pollutants, fine particulate matters (particulate matter with an aerodynamic diameter $\leq 2.5 \mu \mathrm{m}$; $\mathrm{PM}_{2.5}$ ) are thought to be the most important toxicants in urban air (Kaiser 2005). In 2016, World Health Organization (WHO) reported that approximately $92 \%$ of the world's population were residing in places where level of the $\mathrm{PM}_{2.5}$ exceeds $\mathrm{WHO}$ air quality guideline (AQG), an annual average concentration of $10 \mu \mathrm{g} \mathrm{m}^{-3}$ (WHO, 2006). Although studies have indicated a decreasing trend in $\mathrm{PM}_{2.5}$ concentrations in many countries, $\mathrm{PM}_{2.5}$ is still a significant public concern in Taiwan, due to many of the people in Taiwan still live in areas with the $\mathrm{PM}_{2.5}$ exceeds $10 \mu \mathrm{g} \mathrm{m}^{-3}$ and the related adverse health effects such as cardiovascular disease, respiratory disease and cancers have been reported (Cheng and Hsu, 2019; Yang et al., 2018).

Oral cancer $(\mathrm{OC})$ is the fifth leading cause of cancer death and has been the fourth most common cancer in men for more than 10 consecutive years since 2003 in Taiwan (Ministry of Health and Welfare, 2018). In order to prevent the disease onset and to cure or slow the disease progression, the Taiwanese government has implemented the biennial nationwide OC screening focusing on 
adults at a higher risk (betel quid chewers or smokers) since 2004 to detect oral potentially malignant disorder (OPMD) and OC (Chuang et al., 2017). In addition, since betel quid chewing has been identified as a risk factor of OPMD and OC independently (Amarasinghe et al., 2010; Ko et al., 1995; Merchant et al., 2000), and in conjunction with smoking and alcohol drinking (Yen et al., 2007a, 2008; Yen et al., 2008b), the Taiwanese government has reinforced the betel quid chewing prevention and control in recent decades. The betel quid chewing rate among male adults over 18 has been declined from 2007 to 2018 by 59.2\% in Taiwan (Health Promotion Administration, 2019). Although age-standardized OC incidence rate increased continuously in both sexes before 2009, it has become flatten since then (Siewchaisakul et al., 2020a).

The other risk factors of OPMD and OC include exposure to heavy metals (arsenic, nickel, and chromium) at high concentration (Chu et al., 2019; Kaldor et al., 1984; Su et al., 2010; Yuan et al., 2011), human papillomavirus (HPV) infection (Chaturvedi, 2012), presence of metabolic syndrome (MetS) (Yen et al., 2011), and age younger than 70 years (Siewchaisakul et al., 2020a).

Recent studies have shown that the level of $\mathrm{PM}_{2.5}$ was associated with an increased risk in cardiovascular inflammatory marker such as C-reactive protein (CRP) in adults with MetS (Dabass et al., 2018). Other inflammatory markers including T lymphocytes, macrophages, transforming growth factor (TGF)- $\beta 1$, tumor necrosis factor (TNF)- $\alpha$, and interleukin (IL)- 6 were also found as underpinning the link between MetS and OPMD (Chiang et al., 2002; Hsu et al., 2014; Ujpál et al., 2004). This led to the hypothesis that $P M_{2.5}$ may also associate with OPMD.

In 2013, PM 2.5 was noted by International Agency for Research on Cancer (IARC) as carcinogenic to human (Loomis et al., 2013). Carcinomas that have been found to be associated with $\mathrm{PM}_{2.5}$ are lung, leiomyoma, bladder cancer, and OC (Chu et al., 2019; Hamra et al., 2014; Mahalingaiah et al., 2014). Previous study has revealed that the long-term $\mathrm{PM}_{2.5}$ concentrations and daily mean concentrations over $35 \mu \mathrm{g} \mathrm{m}^{-3}$ varied by meteorological conditions and regions in Taiwan (Cheng and Hsu, 2019). Cheng and Hsu's (2019) study prompted us to determine the cut-off point of $\mathrm{PM}_{2.5}$ and also take into account the heterogenous $\mathrm{PM}_{2.5}$ exposure effect on $\mathrm{OC}$ between areas in current study. However, few population-based studies investigated the association between $\mathrm{PM}_{2.5}$ and OC, especially OPMD.

We therefore aimed to elucidate the association between $\mathrm{PM}_{2.5}$ and OPMD/OC, taking heterogeneity between areas into account based on the longitudinal data of air quality monitoring and nationwide $\mathrm{OC}$ screening in Taiwan.

\section{METHODS}

\subsection{Study Population and Data Collection}

\subsubsection{Data source for oral neolplasm}

A retrospective cohort design was conducted in this study. Population in this study was based on the nationwide OC screening program between 2006 and 2016. The program has been launched by Health Promotion Administration (HPA), Taiwan, since 2004. The details have been described by Chuang et al. (2017). The biennial OC screening program with visual inspection was done by the trained dentists and physicians and was targeting high risk population aged 30 years and above who had the habit of either cigarette smoking or betel quid chewing. Those with suspicious lesions would be invited by public health nurses to complete the confirmatory followup examination. We excluded those who had diagnosed with OC before screening and those cancer-free subjects who were diagnosed as epithelial dysplasia in oral cavity.

The definition of oral cancer was according to International Classification of Diseases, $9^{\text {th }}$ Revision-Clinical Modification (codes 140-141, 143-146, and 148-149) and from the International Classification of Diseases, $10^{\text {th }}$ Revision (codes C00-C06, C09-C10, C12-C14) including lip, tongue, gingival, floor of mouth, palate, other parts of mouth, oropharyngeal, hypopharyngeal and unspecified pharyngeal cancer. OPMD was defined when individuals were clinical diagnosed as leukoplakia, erythroleukoplakia, erythroplakia, oral submucous fibrosis, and verrucous hyperplasia.

Data on age at screening, sex, residential area (county/city), unhealthy oral habits (betel quid and cigarettes exposure) were retrieved. Subjects may attend the screening program multiple times. We kept only the latest record of subjects upon the detection of OPMD/OC at screening or before the clinical diagnosis of $\mathrm{OC}$, or the last records of subjects who were free from OPMD/OC. The study 
was approved by the Research Ethics Committee of National Taiwan University Hospital with informed consent pursuant to the regulations of the Institutional Review Board.

\subsubsection{Exposure measurements of $\mathrm{PM}_{2.5}$}

Air quality data measured by Taiwan's Environmental Protection Administration (TEPA) were used to estimate $\mathrm{PM}_{2.5}$ exposures. Since 1993, Taiwan Air Quality Monitoring Network (AQMN) has been established by TEPA to monitor nationwide air quality by 73 monitoring sites distributed in 22 cities/counties (TWEPA, 2019). The complete record of daily continuous monitoring of PM 2.5 were available since August, 2005. Daily $\mathrm{PM}_{2.5}$ concentrations of all monitoring stations in AQMA from 2006 to 2016 were used for the whole year-round measurements and were grouped by city/county.

To investigate the association between $\mathrm{PM}_{2.5}$ and $\mathrm{OPMD} / \mathrm{OC}$, these spatially averaged $\mathrm{PM}_{2.5}$ data were chronically matched to study subjects' screening date by month and the city/county the subjects lived in to represent their $\mathrm{PM}_{2.5}$ exposures.

\subsection{Statistical Analysis}

Descriptive information is reported as frequency and percentage. We first categorized the $\mathrm{PM}_{2.5}$ concentration into dichotomous variable (low and high) using cut-off point of $35 \mu \mathrm{g} \mathrm{m}^{-3}$, the third quartile of the monthly average $\mathrm{PM}_{2.5}$ concentration of all the 22 cities/counties over eleven years. In addition to the dichotomous, we also categorized $\mathrm{PM}_{2.5}$ by $10 \mu \mathrm{g} \mathrm{m}^{-3}$ into 5 groups $\left(<10,10-19,20-29,30-39\right.$, and $\left.40+\mu \mathrm{g} \mathrm{m}^{-3}\right)$. The lowest $\mathrm{PM}_{2.5}$ concentration group $\left(<10 \mu \mathrm{g} \mathrm{m}^{-3}\right)$ was used as the reference group.

Since $\mathrm{PM}_{2.5}$ measurement was based on the level of county/city on monthly basis, we examined the associations between $\mathrm{PM}_{2.5}$ and both OPMD/OC, OPMD or OC using the Bayesian univariable random-effects logistic regression models, treating county-specific $\mathrm{PM}_{2.5}$ effects as random-effect variables. Age (30-49, 50-69, 70+), sex (male, female), and unhealthy oral habits (cigarette smoking only, betel quid chewing only and betel quid chewing and cigarette smoking) are the potential individual risk factors for oral cancer. We further conducted the multivariable analyses controlling the significant confounding factors based on the univariable model. Notably, we did model the $\mathrm{PM}_{2.5}$ as dichotomous and polychotomous in different multivariable models. All tests assumed a two-sided type I error of 0.05 and were performed with SAS version 9.4 (SAS Institute Inc., Cary, NC).

\section{RESULTS AND DISCUSSION}

There were 154,030 OPMD, 23,286 OC cases, and 3,686,729 subjects free from OPMD/OC included in the analyses. Frequency of demographic information and environmental risk exposure of betel quid, cigarette smoking is shown in Table 1. Most of the study population was diagnosed with OPMD in the age group of 30 to 49 years and with OC in the age group of 50 to 69 years. Men who had the habit of cigarette smoking and betel quid chewing were dominant in both OPMD and OC groups.

Fig. 1 shows the average concentrations of $\mathrm{PM}_{2.5}$ by county/city in Taiwan. The highest average concentration was in Chiayi City with the mean of $34.05 \mu \mathrm{g} \mathrm{m}^{-3}$ (standard deviation [SD]: $14.52 \mu \mathrm{g} \mathrm{m}^{-3}$ ). The lowest average concentration was in Taitung County with the mean of $11.82 \mu \mathrm{g} \mathrm{m}^{-3}$ (SD: $3.88 \mu \mathrm{g} \mathrm{m}^{-3}$ ) (Table S1).

\section{1 $\mathrm{PM}_{2.5}$ and Risk of OPMD/OC}

Fig. 2(a) shows the proportions of diagnosed OPMD and OC combined cases by county/city. The county/city with the highest proportion of diagnosed cases was Chiayi City (8.88\%), the same city with the highest average $\mathrm{PM}_{2.5}$ concentration, and the lowest proportion was in Taichung City (1.47\%) (Table S2).

The effects of $\mathrm{PM}_{2.5}$ and other related factors of OPMD/OC are elucidated in Table 2 . In the crude univariable analysis, $\mathrm{PM}_{2.5}$ with concentration $35 \mu \mathrm{g} \mathrm{m}^{-3}$ and above showed a significantly increased risk of OPMD/OC by $4 \%(\mathrm{RR}=1.04,95 \% \mathrm{Cl}: 1.03-1.06)$ compared to concentration lower than $35 \mu \mathrm{g} \mathrm{m}^{-3}$. In the multivariable analysis after adjusting for sex, age, betel quid chewing 
Table 1. Frequency of demographic and risk factor for oral potentially malignant disorders or oral cancer.

\begin{tabular}{|c|c|c|c|c|c|c|c|c|c|c|c|c|}
\hline & \multicolumn{4}{|c|}{ OPMD + OC } & \multicolumn{4}{|c|}{ Only OPMD* } & \multicolumn{4}{|c|}{ Only OC } \\
\hline & Normal & $(\%)$ & Cases & $(\%)$ & Normal & $(\%)$ & Cases & (\%) & Normal & $(\%)$ & Cases & (\%) \\
\hline \multicolumn{13}{|c|}{$\mathrm{PM}_{2.5}\left(\mu \mathrm{g} \mathrm{m}^{-3}\right)$} \\
\hline$<10$ & 107,378 & 2.9 & 4,710 & 2.7 & 107,378 & 2.9 & 4,238 & 2.8 & 107,378 & 2.9 & 472 & 2.0 \\
\hline $10-19$ & $1,224,835$ & 33.2 & 55,677 & 31.4 & $1,224,835$ & 33.2 & 50,065 & 32.5 & $1,224,835$ & 33.2 & 5,612 & 24.1 \\
\hline $20-29$ & $1,501,073$ & 40.7 & 71,242 & 40.2 & $1,501,073$ & 40.7 & 62,009 & 40.3 & $1,501,073$ & 40.7 & 9,233 & 39.7 \\
\hline $30-39$ & 601,697 & 16.3 & 30,343 & 17.1 & 601,697 & 16.3 & 25,413 & 16.5 & 601,697 & 16.3 & 4,930 & 21.2 \\
\hline$\geq 40$ & 251,746 & 6.8 & 15,344 & 8.7 & 251,746 & 6.8 & 12,305 & $8.0 \%$ & 251,746 & 6.8 & 3,039 & 13.1 \\
\hline \multicolumn{13}{|l|}{ Sex } \\
\hline Male & $2,712,478$ & 73.6 & 166,562 & 93.9 & $2,712,478$ & 73.6 & 144,278 & 93.7 & $2,712,478$ & 73.6 & 22,284 & 95.7 \\
\hline Female & 974,251 & 26.4 & 10,754 & 6.1 & 974,251 & 26.4 & 9,752 & 6.3 & 974,251 & 26.4 & 1,002 & 4.3 \\
\hline \multicolumn{13}{|l|}{ Age (years) } \\
\hline 30-49 & $1,719,022$ & 46.6 & 82,952 & 46.8 & $1,719,022$ & 46.6 & 75,172 & 48.8 & $1,719,022$ & 46.6 & 7,780 & 33.4 \\
\hline $50-69$ & $1,446,335$ & 39.2 & 81,049 & 45.7 & $1,446,335$ & 39.2 & 68,272 & 44.3 & $1,446,335$ & 39.2 & 12,777 & 54.9 \\
\hline $70+$ & 521,372 & 14.1 & 13,315 & 7.5 & 521,372 & 14.1 & 10,586 & 6.9 & 521,372 & 14.1 & 2,729 & 11.7 \\
\hline \multicolumn{13}{|l|}{ Habit } \\
\hline$S$ & $1,565,534$ & 42.5 & 44166 & 24.9 & 1565534 & 42.5 & 39260 & 25.5 & 1565534 & 42.5 & 4906 & 21.1 \\
\hline B & 347,703 & 9.4 & 8795 & 5.0 & 347703 & 9.4 & 7210 & 4.7 & 347703 & 9.4 & 1585 & 6.8 \\
\hline BS & $1,773,492$ & 48.1 & 124355 & 70.1 & 1773492 & 48.1 & 107560 & 69.8 & 1773492 & 48.1 & 16795 & 72.1 \\
\hline
\end{tabular}

*(For OPMD the concentration was grouped in 5 groups from $<15 \mu \mathrm{g} \mathrm{m}^{-3}$ to $\geq 45 \mu \mathrm{g} \mathrm{m}{ }^{-3}$ for only OPMD B: Betel quid chewing only; BS: Betel quid chewing and cigarette smoking; S: cigarette smoking only

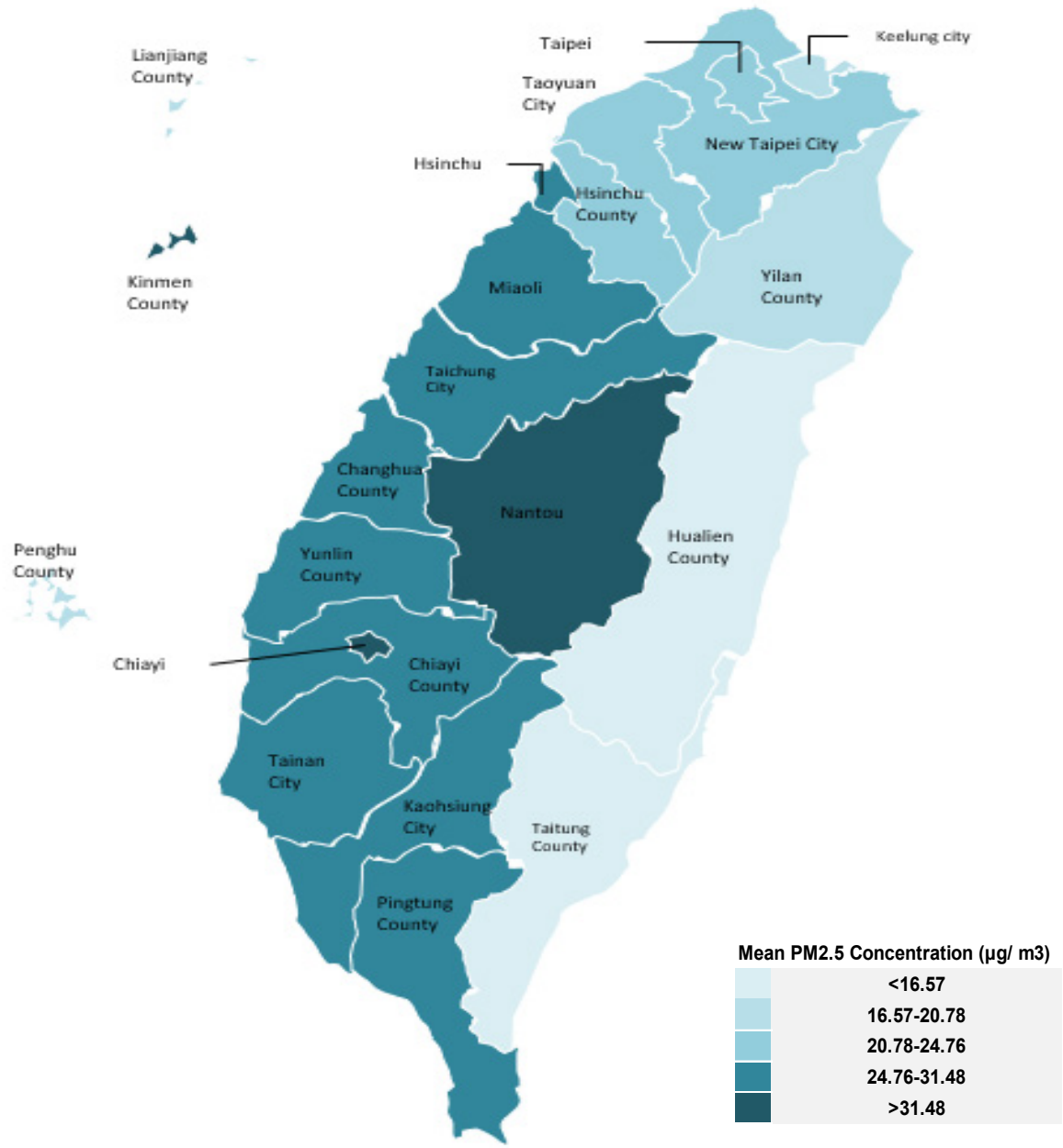

Fig. 1. Geographically gradients of monthly average $\mathrm{PM}_{2.5}$ concentration by county/city. Quintile was used for classification of pattern. 

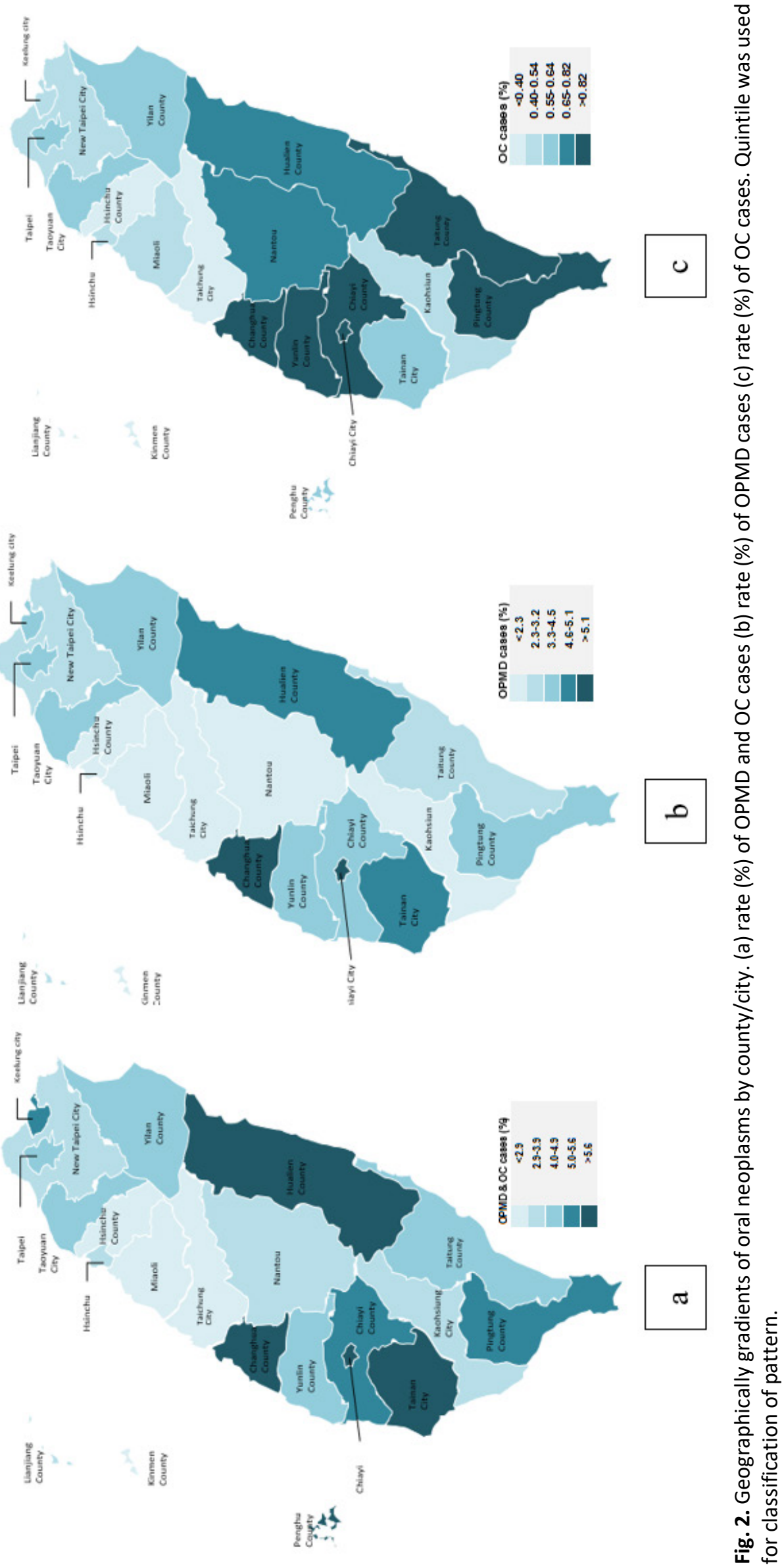
Table 2. Univariable and multivariable Bayesian random-effect logistic regression models for oral neoplasm (OPMD + OC).

\begin{tabular}{|c|c|c|c|c|}
\hline Variables & RR & $(95 \% \mathrm{Cl})$ & aRR & $(95 \% \mathrm{Cl})$ \\
\hline \multicolumn{5}{|c|}{$\mathrm{PM}_{2.5}\left(\mathrm{vs}<35 \mu \mathrm{g} \mathrm{m}^{-3}\right)^{*}$} \\
\hline$\geq 35 \mu \mathrm{g} \mathrm{m}^{-3}$ & 1.04 & $(1.03,1.06)$ & 1.11 & $(1.09,1.13)$ \\
\hline \multicolumn{5}{|c|}{$\mathrm{PM}_{2.5}\left(\mathrm{vs}<10 \mu \mathrm{g} \mathrm{m}^{-3}\right)$} \\
\hline $10-19 \mu \mathrm{g} \mathrm{m}^{-3}$ & 1.10 & $(1.07,1.14)$ & 1.20 & $(1.16,1.24)$ \\
\hline $20-29 \mu \mathrm{g} \mathrm{m}^{-3}$ & 1.17 & $(1.13,1.21)$ & 1.36 & $(1.31,1.40)$ \\
\hline $30-39 \mu \mathrm{g} \mathrm{m}^{-3}$ & 1.16 & $(1.13,1.20)$ & 1.39 & $(1.34,1.44)$ \\
\hline$\geq 40 \mu \mathrm{g} \mathrm{m}^{-3}$ & 1.24 & $(1.19,1.29)$ & 1.52 & $(1.46,1.57)$ \\
\hline \multicolumn{5}{|l|}{ Sex (vs Female) } \\
\hline Male & 5.56 & $(5.46,5.66)$ & 4.81 & $(4.72,4.91)$ \\
\hline \multicolumn{5}{|c|}{ Age group (vs 70+, years) } \\
\hline $30-49$ & 1.89 & $(1.85,1.92)$ & 1.99 & $(1.95,2.02)$ \\
\hline $50-69$ & 2.19 & $(2.15,2.23)$ & 2.29 & $(2.24,2.33)$ \\
\hline \multicolumn{5}{|l|}{ Habit (vs S) } \\
\hline B & 0.90 & $(0.88,0.92)$ & 1.23 & $(1.20,1.26)$ \\
\hline$B+S$ & 2.49 & $(2.46,2.51)$ & 2.26 & $(2.23,2.28)$ \\
\hline
\end{tabular}

B: Betel quid chewing only; BS: Betel quid chewing and cigarette smoking; $\mathrm{Cl}$ : incredible interval; S: cigarette smoking only; ${ }^{*} \mathrm{PM}_{2.5}$ with dichotomous were estimated in different model, adjusted by sex, age, and oral habit (betel quid chewing and cigarette smoking).

and cigarette smoking, the significant effect of $\mathrm{PM}_{2.5}$ on $\mathrm{OPMD} / \mathrm{OC}$ still remains with an increased adjusted risk of $11 \%$ (adjusted $\mathrm{RR}(\mathrm{aRR})=1.11,95 \% \mathrm{Cl}: 1.09^{-1} .13$ ). When categorized $\mathrm{PM}_{2.5}$ by $10 \mu \mathrm{g} \mathrm{m}^{-3}$, the risks of OPMD/OC were significantly higher in the groups in the univariable and the multivariable analyses. The aRRs of OPMD/OC were 1.20 (95\% Cl: $1.16-1.24), 1.36$ (95\% Cl: 1.31-1.40), 1.39 (95\% Cl: 1.34-1.44), and 1.52 (95\% Cl: 1.46-1.57) in the $\mathrm{PM}_{2.5}$ concentration groups of 10-19, 20-29, 30-39, $\geq 40 \mu \mathrm{g} \mathrm{m}^{-3}$, respectively, after adjusting for age, sex, betel quid chewing and cigarettes smoking (Table 2 ).

Dose-response relationships of oral habits and OPMD or OC has been demonstrated in previous studies and we chose some typical papers with comparable attributes of oral habits in Taiwan or India (Madathil et al., 2016; Yang et al., 2010; Yen et al., 2007; Znaor et al., 2003). As shown in previous studies, the higher the quantity of cigarette smoking or betel quid chewing, the higher the risk of OPMD/OC. As shown in Fig. 3(a), the concentration-dependent effect of $\mathrm{PM}_{2.5}$ can be observed in comparison with magnitude of effects of traditional risk factors (betel quid and cigarette smoking).

Many studies have reported that exposure to $\mathrm{PM}_{2.5}$ increased the risk of lung cancer or respiratory diseases (Ghazipura et al., 2019; Hamra et al., 2014; Hopke et al., 2019; Raaschou-Nielsen et al., 2016). Undoubtedly, oral is one of the exposure routes to these ultrafine particles. Biological evidence has been established for plausible mechanisms between $\mathrm{PM}_{2.5}$ and carcinogenesis, such as increased oxidative stress, induced DNA damages and DNA mutations, inflammatory responses, and may lead to the occurrence of malignant tumor (Feng et al., 2016; Ghio et al., 2012). Furthermore, OC/OPMD is mostly developed from the squamous cell, in that accounted to 80$90 \%$ of oral malignancy (Johnson et al., 2011). Thus, inflammatory response maybe be one of the mechanisms underpinning the association between $\mathrm{PM}_{2.5}$ and OPMD/OC.

\section{2 $\mathrm{PM}_{2.5}$ and Risk of OPMD}

The highest average $\mathrm{PM}_{2.5}$ concentration was noted in Chiayi City with the mean of $34.00 \mu \mathrm{g} \mathrm{m}^{-3}$ (SD: $14.50 \mu \mathrm{g} \mathrm{m}^{-3}$ ) and the lowest average concentration was found in Taitung County with the mean of $11.81 \mu \mathrm{g} \mathrm{m}^{-3}$ (SD: $3.88 \mu \mathrm{g} \mathrm{m}^{-3}$ ) (Table S3). The proportion of diagnosed OPMD cases by county/city was shown in Fig. 2(b). The highest proportion of diagnosed cases was found in Chiayi City $(7.83 \%)$, followed by Penghu County $(6.48 \%)$ and Changhua County $(6.26 \%)$ and the lowest proportion was found in Hsinchu County (1.23\%), see Table S4.

The effect of $\mathrm{PM}_{2.5}$ and others related factors on OPMD are elucidated in Table 3 . In the 

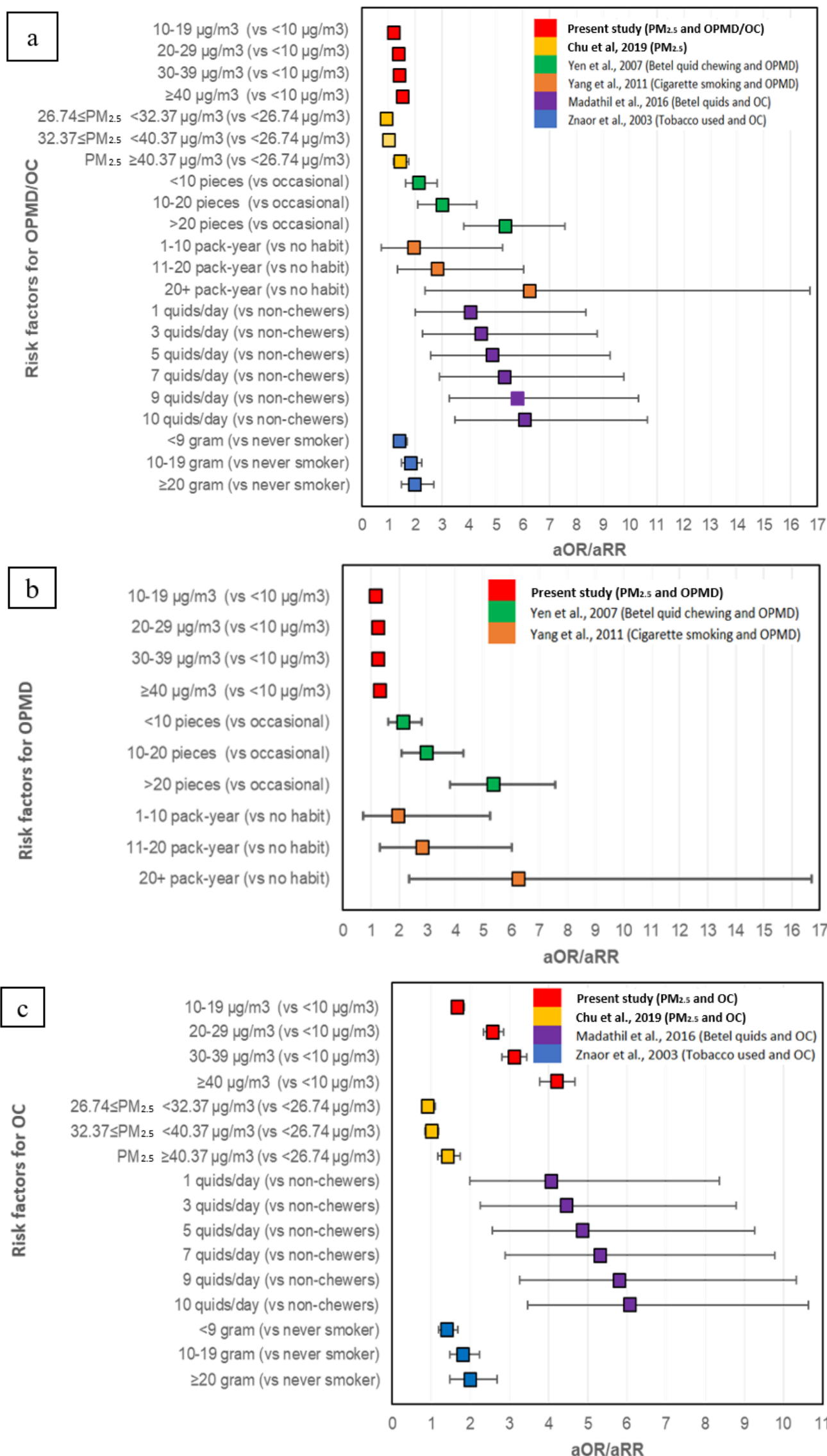

Fig. 3. Adjusted odds/relative risk ratio of $\mathrm{PM}_{2.5}$ and other risk factors for (a) OPMD or oral cancer (b) OPMD and (c) OC. 
Table 3. Univariable and multivariable Bayesian random-effect logistic regression models for OPMD.

\begin{tabular}{|c|c|c|c|c|}
\hline Variables & $\mathrm{RR}$ & $(95 \% \mathrm{Cl})$ & $\mathrm{aRR}$ & $(95 \% \mathrm{Cl})$ \\
\hline \multicolumn{5}{|c|}{$\mathrm{PM}_{2.5}\left(\mathrm{vs}<35 \mu \mathrm{g} \mathrm{m}^{-3}\right)^{*}$} \\
\hline$\geq 35 \mu \mathrm{g} \mathrm{m}^{-3}$ & 0.98 & $(0.97,1.00)$ & 1.04 & $(1.03,1.06)$ \\
\hline \multicolumn{5}{|c|}{$\mathrm{PM}_{2.5}\left(\mathrm{vs}<10 \mu \mathrm{g} \mathrm{m}^{-3}\right)$} \\
\hline $10-19 \mu \mathrm{g} \mathrm{m}^{-3}$ & 1.05 & $(1.02,1.09)$ & 1.15 & $(1.11,1.19)$ \\
\hline $20-29 \mu \mathrm{g} \mathrm{m}^{-3}$ & 1.08 & $(1.04,1.11)$ & 1.26 & $(1.21,1.30)$ \\
\hline $30-39 \mu \mathrm{g} \mathrm{m}^{-3}$ & 1.04 & $(1.01,1.08)$ & 1.25 & $(1.20,1.29)$ \\
\hline$\geq 40 \mu \mathrm{g} \mathrm{m}^{-3}$ & 1.06 & $(1.03,1.10)$ & 1.30 & $(1.25,1.35)$ \\
\hline \multicolumn{5}{|l|}{ Sex (vs Female) } \\
\hline Male & 5.32 & $(5.20,5.43)$ & 4.57 & $(1.50,1.54)$ \\
\hline \multicolumn{5}{|c|}{ Age group (vs $70+$, years) } \\
\hline $30-49$ & 2.15 & $(2.11,2.20)$ & 2.23 & $(2.18,2.28)$ \\
\hline $50-69$ & 2.32 & $(2.28,2.37)$ & 2.40 & $(2.34,2.45)$ \\
\hline \multicolumn{5}{|l|}{ Habit (vs S) } \\
\hline B & 0.83 & $(0.81,0.85)$ & 1.15 & $(1.12,1.18)$ \\
\hline$B+S$ & 2.42 & $(2.39,2.45)$ & 2.23 & $(2.20,2.26)$ \\
\hline
\end{tabular}

B: Betel quid chewing only; BS: Betel quid chewing and cigarette smoking; $\mathrm{Cl}$ : incredible interval; S: cigarette smoking only; ${ }^{*} \mathrm{PM}_{2.5}$ with dichotomous were estimated in different model, adjusted by sex, age, and oral habit (betel quid chewing and cigarette smoking).

univariable analysis, $\mathrm{PM}_{2.5}$ exposure was insignificant associated with OPMD. However, higher $\mathrm{PM}_{2.5}$ significantly increased the risk of OPMD by $4 \%$ ( $\left.\mathrm{aRR}=1.04,95 \% \mathrm{Cl}: 1.03-1.06\right)$ in the multivariable analysis. When categorized $\mathrm{PM}_{2.5}$ by $10 \mu \mathrm{g} \mathrm{m}^{-3}$, the risks of OPMD/OC were significantly higher in the $\mathrm{PM}_{2.5}>10 \mu \mathrm{g} \mathrm{m}^{-3}$ concentration groups in the univariable and the multivariable analyses. These concentration-dependent relationships can be observed, and compared to the magnitude of effects of traditional risk factors (betel quid and cigarette smoking) as shown in Fig. 3(b).

Recent study has shown one of the cardiovascular related-inflammatory markers, the CRP was increased with high level of $\mathrm{PM}_{2.5}$ in adults with MetS (Dabass et al., 2018). MetS has been found to be associated with OPMD and several cancers (Braun et al., 2011; Ku et al., 2019; Siewchaisakul et al., 2020; Yen et al., 2011). Pro-inflammatory markers, including TNF- $\alpha$, IL-6 and CRP were shown to be the underlying mechanism between MetS and OPMD as well (Hsu et al., 2014).

\section{3 $\mathrm{PM}_{2.5}$ and Risk of OC}

The highest average $\mathrm{PM}_{2.5}$ concentration was noted in Chiayi City with the mean of $33.98 \mu \mathrm{g} \mathrm{m}^{-3}$ (SD: $14.48 \mu \mathrm{g} \mathrm{m}^{-3}$ ) and the lowest average concentration was found in Taitung County with the mean of $11.83 \mu \mathrm{g} \mathrm{m}^{-3}$ (SD: $3.88 \mu \mathrm{g} \mathrm{m}^{-3}$ ) (Table S5). The proportion of diagnosed OC cases by county/city was shown in Fig. 2(c). The highest proportion of diagnosed cases was found in Chiayi City $(1.23 \%)$, followed by Changhua County (1.23\%) and Yunlin County $(1.00 \%)$ and the lowest proportion was found in Lianjiang County with no case found in our study, see Table S6.

The effect of $\mathrm{PM}_{2.5}$ and others related factors on $\mathrm{OC}$ are elucidated in Table 4 . In the univariable analysis, $\mathrm{PM}_{2.5}$ with concentration greater than or equal to $35 \mu \mathrm{g} \mathrm{m}^{-3}$ shown significantly increased risk of OC by $44 \%(R R=1.44,95 \% \mathrm{Cl}: 1.39-1.50)$ compared to those lower than $35 \mu \mathrm{g} \mathrm{m}^{-3}$. In the multivariable analysis, higher $\mathrm{PM}_{2.5}$ exposure statistically increased the risk of OC by $55 \%$ (aRR = 1.55, 95\% Cl: 1.49-1.60) compared to low $\mathrm{PM}_{2.5}$ exposure. When categorized $\mathrm{PM}_{2.5}$ by $10 \mu \mathrm{g} \mathrm{m}^{-3}$ in the multivariable analysis, $\mathrm{PM}_{2.5}$ still increased risk of $\mathrm{OC}$ with higher concentrations. $\mathrm{PM}_{2.5}$ with concentration of $10-19 \mu \mathrm{g} \mathrm{m}^{-3}$ has greater risk of OC by 1.68-fold compared to those lower than $10 \mu \mathrm{g} \mathrm{m}^{-3}$ (aRR $\left.=1.68,95 \% \mathrm{Cl}: 1.52-1.85\right)$. This result is consistent with the concentrations of 20-29, 30-39, $\geq 40 \mu \mathrm{g} \mathrm{m}^{-3}$ compared to $<10 \mu \mathrm{g} \mathrm{m}^{-3}$ in which the aRR were 2.58 (95\% Cl: $2.33-$ 2.85), 3.12 (95\% Cl: $2.81-3.45)$, and 4.21 (95\% Cl: 3.78-4.68), respectively (Table 4).

These concentration-dependent relationships were commensurate with the magnitude of effects of traditional risk factors (betel quid and cigarette smoking) as shown in Fig. 3(c). The 
Table 4. Univariable and multivariable Bayesian random-effect logistic regression models for OC.

\begin{tabular}{|c|c|c|c|c|}
\hline Variables & RR & $(95 \% \mathrm{Cl})$ & aRR & $(95 \% \mathrm{Cl})$ \\
\hline \multicolumn{5}{|c|}{$\mathrm{PM}_{2.5}\left(\mathrm{vs}<35 \mu \mathrm{g} \mathrm{m}^{-3}\right)^{*}$} \\
\hline$\geq 35 \mu \mathrm{g} \mathrm{m}^{-3}$ & 1.44 & $(1.39,1.50)$ & 1.55 & $(1.49,1.60)$ \\
\hline \multicolumn{5}{|c|}{$\mathrm{PM}_{2.5}\left(\mathrm{vs}<10 \mu \mathrm{g} \mathrm{m}^{-3}\right)$} \\
\hline $10-19 \mu \mathrm{g} \mathrm{m}^{-3}$ & 1.57 & $(1.42,1.73)$ & 1.68 & $(1.52,1.85)$ \\
\hline $20-29 \mu \mathrm{g} \mathrm{m}^{-3}$ & 2.27 & $(2.04,2.51)$ & 2.58 & $(2.33,2.85)$ \\
\hline $30-39 \mu \mathrm{g} \mathrm{m}^{-3}$ & 2.65 & $(2.38,2.93)$ & 3.12 & $(2.81,3.45)$ \\
\hline$\geq 40 \mu \mathrm{g} \mathrm{m}^{-3}$ & 3.44 & $(3.09,3.79)$ & 4.21 & $(3.78,4.68)$ \\
\hline \multicolumn{5}{|l|}{ Sex (vs Female) } \\
\hline Male & 7.99 & $(7.50,8.50)$ & 7.42 & $(6.95,7.94)$ \\
\hline \multicolumn{5}{|c|}{ Age group (vs 70+, years) } \\
\hline $30-49$ & 0.86 & $(0.83,0.90)$ & 1.00 & $(0.96,1.04)$ \\
\hline $50-69$ & 1.69 & $(1.62,1.75)$ & 1.90 & $(1.82,1.98)$ \\
\hline \multicolumn{5}{|l|}{ Habit (vs S) } \\
\hline B & 1.45 & $(1.38,1.54)$ & 1.82 & $(1.72,1.93)$ \\
\hline$B+S$ & 3.02 & $(2.93,3.12)$ & 2.48 & $(2.40,2.56)$ \\
\hline
\end{tabular}

$\mathrm{B}$ : Betel quid chewing only; BS: Betel quid chewing and cigarette smoking; $\mathrm{Cl}$ : incredible interval; S: cigarette smoking only; ${ }^{*} \mathrm{PM}_{2.5}$ with dichotomous were estimated in different model, adjusted by sex, age, and oral habit (betel quid chewing and cigarette smoking).

higher the quantity of cigarette smoking or betel quid chewing, the higher the risk of OC. The same trend could also be found for the association between $\mathrm{PM}_{2.5}$ exposure and risk of OC, consistent with previous study reported by Chu et al. (2019).

The components of $\mathrm{PM}_{2.5}$, such as arsenic, nickel, chromium, asbestos, and polycyclic aromatic hydrocarbons (PAHs), have been found to be associated with an increased OC risk (GutiérrezCastillo et al., 2006; Paget-Bailly et al., 2012; Su et al., 2010; Yuan et al., 2011). The carcinogenetic potential of chronic $\mathrm{PM}_{2.5}$ exposure has been widely demonstrated in animal studies, with genome wide epigenetic and RNA transcription changes and malignant cancer cell behaviors such as crosstalk between epithelial-mesenchymal transition (EMT) and cancer stem cells (CSCs) properties which may lead to enhanced tumorigenicity and promote cancer cell progression (Yang and Xiao, 2018; Lee et al., 2020). These together may explain the association of $\mathrm{PM}_{2.5}$ and OPMD/OC, as well the reason why the association between $\mathrm{PM}_{2.5}$ and $\mathrm{OC}$ is more profound than OPMD in this study.

\subsection{Comparison between Studies}

To our knowledge, only limited epidemiological studies have reported $\mathrm{PM}_{2.5}$ and $\mathrm{OC}$ risk. A previous study in Taiwan has reported that an increased risk of OC among men who were exposed to $\mathrm{PM}_{2.5}$ concentration over $40.37 \mu \mathrm{g} \mathrm{m}^{-3}$ (aOR $=1.43,95 \% \mathrm{Cl}: 1.17-1.74$ ), compared with $26.74 \mu \mathrm{g} \mathrm{m}^{-3}<\mathrm{PM}_{2.5}$ (Chu et al., 2019). We targeted smokers and/or betel quid chewers, the high-risk population of OPMD/OC and found that $\mathrm{PM}_{2.5}$ with concentration of $35 \mu \mathrm{g} \mathrm{m}^{-3}$ and higher has a significant increased risk of $O C$, and the effect magnitude in associated with OC was even higher compared to others. We also found that $\mathrm{PM}_{2.5}$ with concentration of $10 \mu \mathrm{g} \mathrm{m}^{-3}$ and higher has a significant increased risk of OPMD. The novelties of this study could be emphasized by comparing to the previous studies. First, our study is a longitudinal cohort study with 11 years followed-up of OPMD/OC nationwide screening data. This makes allowance for the identification of OPMD cases, the precursor of invasive oral cancer, as well as the information on both sexes and unhealthy oral habits. Second, we took into account the geographic variations when evaluating the $\mathrm{OC}$ risk in association with $\mathrm{PM}_{2.5}$ in our study. We consider monthly average $\mathrm{PM}_{2.5}$ concentration as a random effect in our model since this exposure indicator is a hierarchical factor rather than an individual one. Last but not least, an ecological study by Su et al. (2019) presented the geographical variations on the association between $\mathrm{PM}_{2.5}$ and cancer incidence in Taiwan. Su et al. (2019) also reported a significant dose-response relationship between $\mathrm{PM}_{2.5}$ and OC incidence with spearman correlation ranged between 0.56-0.59 in men. However, several potential risk factors such as habitual smoking or betel quid chewing were not considered in their study. 


\subsection{Limitation}

Some limitations in this study should be noted. First, we do not have exact data on individuals' daily $\mathrm{PM}_{2.5}$ exposures. Therefore, we estimated monthly $\mathrm{PM}_{2.5}$ concentration in average by areas. Second, we used data based on nationwide OC screening program in which targeted population were those who only experienced betel quid chewing or smoking behavior. Thus, generalization of our study results would limit to smokers and/or betel quid chewers. Third, the PM2.5 exposure duration and the exposure history has not been considered in this study. Those who were diagnosed as oral cancer might have been continuously exposed to high level of PM2.5. Finally, there are still numerous variables related to OPMD/OC risk such as genetic, family history of OC, history of chronic diseases and other potential carcinogenic compounds, which we haven't considered in this study.

\section{CONCLUSIONS}

To our knowledge, this is the first study to investigate the association between $\mathrm{PM}_{2.5}$ and $O P M D / O C$ at nationwide level. Based on the longitudinal nationwide $O C$ data, we found that $\mathrm{PM}_{2.5}$ exposure was linked to an increased risk of OPMD/OC among smokers and/or betel quid chewers. Our results also demonstrated the spatial variations for $\mathrm{PM}_{2.5}$ concentration and OPMD/OC. This information would beneficial to OPMD/OC prevention policy in some specific counties or cities. Future studies are warranted to investigate the effect of personal $\mathrm{PM}_{2.5}$ exposure on OPMD/OC risk.

\section{ACKNOWLEDGMENTS}

We thank the Research Ethics Committee of National Taiwan University Hospital approved this project, and granted a waiver for informed consent (202002091W) pursuant to the regulations of the Institutional Review Board. This work was financially supported by the "National Taiwan University Higher Education Sprout Project (NTU-110L8810)" within the framework of the Higher Education Sprout Project by the Ministry of Education (MOE) in Taiwan.

\section{SUPPLEMENTARY MATERIAL}

Supplementary material for this article can be found in the online version at https://doi. org/10.4209/aaqr.210060

\section{REFERENCES}

Amarasinghe, H.K., Usgodaarachchi, U.S., Johnson, N.W., Lalloo, R., Warnakulasuriya, S. (2010). Betel-quid chewing with or without tobacco is a major risk factor for oral potentially malignant disorders in Sri Lanka: A case-control study. Oral Oncol. 46, 297-301. https://doi.org/10.1016/ j.oraloncology.2010.01.017

Braun, S., Bitton-Worms, K., LeRoith, D. (2011). The link between the metabolic syndrome and cancer. Int. J. Biol. Sci. 7, 1003-1015. https://doi.org/10.7150/ijbs.7.1003

Chaturvedi, A.K. (2012). Epidemiology and clinical aspects of HPV in head and neck cancers. Head Neck Pathol. 6, 16-24. https://doi.org/10.1007/s12105-012-0377-0

Cheng, F.Y., Hsu, C.H. (2019). Long-term variations in $\mathrm{PM}_{2.5}$ concentrations under changing meteorological conditions in Taiwan. Sci Rep. 9, 6635. https://doi.org/10.1038/s41598-019-43104-x

Chiang, C.P., Wu, H.Y., Liu, B.Y., Wang, J.T., Kuo, M.Y. (2002). Quantitative analysis of immunocompetent cells in oral submucous fibrosis in Taiwan. Oral Oncol. 38, 56-63. https://doi.org/10.1016/s1368-8375(01)00026-4

Chu, Y.H., Kao, S.W., Tantoh, D.M., Ko, P.C., Lan, S.J., Liaw, Y.P. (2019). Association between fine particulate matter and oral cancer among Taiwanese men. J. Investig. Med. 67, 34-38. https://doi.org/10.1136/jim-2016-000263 
Chuang, S.L., Su, W.W., Chen, S.L., Yen, A.M., Wang, C.P., Fann, J.C., Chiu, S.Y., Lee, Y.C., Chiu, H.M., Chang, D.C., Jou, Y.Y., Wu, C.Y., Chen, H.H., Chen, M.K., Chiou, S.T. (2017). Population-based screening program for reducing oral cancer mortality in 2,334,299 Taiwanese cigarette smokers and/or betel quid chewers. Cancer 123, 1597-1609. https://doi.org/10.1002/cncr.30517

Dabass, A., Talbott, E.O., Rager, J.R., Marsh, G.M., Venkat, A., Holguin, F., Sharma, R.K. (2018). Systemic inflammatory markers associated with cardiovascular disease and acute and chronic exposure to fine particulate matter air pollution ( $\mathrm{PM}_{2.5}$ ) among US NHANES adults with metabolic syndrome. Environ. Res. 161, 485-491. https://doi.org/10.1016/j.envres.2017.11.042

Environmental Protection Administration, ROC (Taiwan) (TWEPA) (2019). Taiwan Air Quality Monitoring Network. http://taqm.epa.gov.tw/taqm/en/YearlyDataDownload.aspx (accessed 1 October 1 2019)

Feng, S., Gao, D., Liao, F., Zhou, F., Wang, X. (2016). The health effects of ambient $\mathrm{PM}_{2.5}$ and potential mechanisms. Ecotoxicol. Environ. Saf. 128, 67-74. https://doi.org/10.1016/j.ecoenv. 2016.01.030

Ghio, A.J., Carraway, M.S., Madden, M.C. (2012). Composition of air pollution particles and oxidative stress in cells, tissues, and living systems. J. Toxicol. Environ. Health Part B 15, 1-21. https://doi.org/10.1080/10937404.2012.632359

Gutiérrez-Castillo, M.E., Roubicek, D.A., Cebrián-García, M.E., De Vizcaya-Ruíz, A., Sordo-Cedeño, M., Ostrosky-Wegman, P. (2006). Effect of chemical composition on the induction of DNA damage by urban airborne particulate matter. Environ. Mol. Mutagen. 47, 199-211. https://doi.org/10.1002/em.20186

Hamra, G.B., Guha, N., Cohen, A., Laden, F., Raaschou-Nielsen, O., Samet, J.M., Vineis, P., Forastiere, F., Saldiva, P., Yorifuji, T., Loomis, D. (2014). Outdoor particulate matter exposure and lung cancer: a systematic review and meta-analysis. Environ. Health Perspect. 122, 906911. https://doi.org/10.1289/ehp/1408092

Health Promotion Administration (2019). Annual Report. 2019. https://www.hpa.gov.tw/E ngPages/Detail. aspx? nodeid $=1070 \&$ pid $=12811$

Hopke, P.K., Croft, D., Zhang, W., Lin, S., Masiol, M., Squizzato, S., Thurston, S.W., van Wijngaarden, E., Utell, M.J., Rich, D.Q. (2019). Changes in the acute response of respiratory diseases to $\mathrm{PM}_{2.5}$ in New York State from 2005 to 2016. Sci. Total Environ. 677, 328-339. https://doi.org/10.1016/j.scitotenv.2019.04.357

Hsu, H.J., Yang, Y.H., Shieh, T.Y., Chen, C.H., Kao, Y.H., Yang, C.F., Ko, E.C. (2014). Role of cytokine gene (interferon- $\gamma$, transforming growth factor- $\beta 1$, tumor necrosis factor- $\alpha$, interleukin- 6 , and interleukin-10) polymorphisms in the risk of oral precancerous lesions in Taiwanese. Kaohsiung J. Med. Sci. 30, 551-558. https://doi.org/10.1016/j.kjms.2014.09.003

Johnson, N.W., Jayasekara, P., Amarasinghe, A.A. (2011). Squamous cell carcinoma and precursor lesions of the oral cavity: Epidemiology and aetiology. Periodontol 2000 57, 19-37. https://doi.org/10.1111/j.1600-0757.2011.00401.x

Kaiser, J. (2005). Epidemiology. Mounting evidence indicts fine-particle pollution. Science 307, 1858-1861. https://doi.org/10.1126/science.307.5717.1858a

Kaldor, J., Harris, J.A., Glazer, E., Glaser, S., Neutra, R., Mayberry, R., Nelson, V., Robinson, L., Reed, D. (1984). Statistical association between cancer incidence and major-cause mortality, and estimated residential exposure to air emissions from petroleum and chemical plants. Environ. Health Perspect. 54, 319-332. https://doi.org/10.1289/ehp.8454319

Ko, Y.C., Huang, Y.L., Lee, C.H., Chen, M.J., Lin, L.M., Tsai, C.C. (1995). Betel quid chewing, cigarette smoking and alcohol consumption related to oral cancer in Taiwan. J. Oral Pathol. Med. 24, 450-453. https://doi.org/10.1111/j.1600-0714.1995.tb01132.x

Kouassi, K.S., Billet, S., Garçon, G., Verdin, A., Diouf, A., Cazier, F., Djaman, J., Courcot, D., Shirali, P. (2010). Oxidative damage induced in A549 cells by physically and chemically characterized air particulate matter ( $\left.\mathrm{PM}_{2.5}\right)$ collected in Abidjan, Côte d'Ivoire. J. Appl. Toxicol. 30, 310-320. https://doi.org/10.1002/jat.1496

Ku, M.S., Fann, J.C., Chiu, S.Y., Chen, H.H., Hsu, C.Y. (2019). Elucidating bidirectional relationship between metabolic syndrome and elevated faecal haemoglobin concentration: A Taiwanese community-based cohort study. BMJ Open 9, e021153. https://doi.org/10.1136/bmjopen2017-021153

Lee, C.W., Vo, T., Wu, C.Z., Chi, M.C., Lin, C.M., Fang, M.L., Lee, I.T. (2020). The inducible role of 
ambient particulate matter in cancer progression via oxidative stress-mediated reactive oxygen species pathways: A recent perception. Cancers 1, 2505. https://doi.org/10.3390/canc ers12092505

Loomis, D., Grosse, Y., Lauby-Secretan, B., Ghissassi, F.E., Bouvard, V., Benbrahim-Tallaa, L., Guha, N., Baan, R., Mattock, H., Straif, K. (2013). The carcinogenicity of outdoor air pollution. Lancet Oncol. 14, 1262-1263. https://doi.org/10.1016/S1470-2045(13)70487-X

Madathil, S.A., Rousseau, M.C., Wynant, W., Schlecht, N.F., Netuveli, G., Franco, E.L., Nicolau, B. (2016). Nonlinear association between betel quid chewing and oral cancer: Implications for prevention. Oral Oncol. 60, 25-31. https://doi.org/10.1016/j.oraloncology.2016.06.011

Mahalingaiah, S., Hart, J.E., Laden, F., Terry, K.L., Boynton-Jarrett, R., Aschengrau, A., Missmer, S.A. (2014). Air pollution and risk of uterine leiomyomata. Epidemiology 25, 682-688. https://doi.org/10.1097/EDE.0000000000000126

Merchant, A., Husain, S.S., Hosain, M., Fikree, F.F., Pitiphat, W., Siddiqui, A.R., Hayder, S.J., Haider, S.M., Ikram, M., Chuang, S.K., Saeed, S.A. (2000). Paan without tobacco: An independent risk factor for oral cancer. Int. J. Cancer. 86, 128-131. https://doi.org/10.1002/(sici)10970215(20000401)86:1<128::aid-ijc20>3.0.co;2-m

Ministry of Health and Welfare, Taiwan (2018). Cancer Registry Annual Report. 2018. https://www.hpa.gov.tw/Pages/Detail.aspx? nodeid=269\&pid=13498

Paget-Bailly, S., Cyr, D., Luce, D. (2012). Occupational exposures to asbestos, polycyclic aromatic hydrocarbons and solvents, and cancers of the oral cavity and pharynx: A quantitative literature review. Int. Arch. Occup. Environ. Health 85, 341-351. https://doi.org/10.1007/s004 20-011-0683-y

Raaschou-Nielsen, O., Beelen, R., Wang, M., Hoek, G., Andersen, Z.J., Hoffmann, B., Stafoggia, M., Samoli, E., Weinmayr, G., Dimakopoulou, K., Nieuwenhuijsen, M., Xun, W.W., Fischer, P., Eriksen, K.T., Sørensen, M., Tjønneland, A., Ricceri, F., de Hoogh, K., Key, T., Eeftens, M., et al. (2016). Particulate matter air pollution components and risk for lung cancer. Environ. Int. 87, 66-73. https://doi.org/10.1016/j.envint.2015.11.007

Siewchaisakul, P., Sarakarn, P., Vatanasapt, P., Chen, S.L., Yen, A.M. (2020a). Sex differences in the heterogeneous dynamic incidence of oral cancer: A comparison between Taiwan and Thailand. Biomed Res. Int. 2020, 9321246. https://doi.org/10.1155/2020/9321246

Siewchaisakul, P., Wang, S.T., Peng, S.M., Sarakarn, P., Chen, L.S., Chen, T.H., Yeh, Y.P., Yen, A.M. (2020b). Effect of metabolic syndrome on incidence of oral potentially malignant disorder: A prospective cohort study in Taiwan. BMJ Open 10, e041971. https://doi.org/10.1136/bmjopen2020-041971

Su, C.C., Lin, Y.Y., Chang, T.K., Chiang, C.T., Chung, J.A., Hsu, Y.Y., Lian, I. (2010). Incidence of oral cancer in relation to nickel and arsenic concentrations in farm soils of patients' residential areas in Taiwan. BMC Public Health.10, 67. https://doi.org/10.1186/1471-2458-10-67

Su, S.Y., Liaw, Y.P., Jhuang, J.R., Hsu, S.Y., Chiang, C.J., Yang, Y.W., Lee, W.C. (2019). Associations between ambient air pollution and cancer incidence in Taiwan: an ecological study of geographical variations. BMC Public Health 19, 1496. https://doi.org/10.1186/s12889-0197849-z

Ujpál, M., Matos, O., Bíbok, G., Somogyi, A., Szabó, G., Suba, Z. (2004). Diabetes and oral tumors in Hungary: Epidemiological correlations. Diabetes Care 27, 770-774. https://doi.org/10.2337/ diacare.27.3.770

World Health Organization (WHO) (2006). Air quality guidelines: Global update 2005: Particulate matter, ozone, nitrogen dioxide, and sulfur dioxide. World Health Organization.

Yang, B., Xiao, C. (2018). PM2.5 exposure significantly improves the exacerbation of A549 tumorbearing CB17-SCID mice. Environ. Toxicol. Pharmacol. 60, 169-175. https://doi.org/10.1016/ j.etap.2018.04.025

Yang, X., Jiang, L., Zhao, W., Xiong, Q., Zhao, W., Yan, X. (2018). Comparison of ground-based $\mathrm{PM}_{2.5}$ and $\mathrm{PM}_{10}$ concentrations in China, India, and the U.S. Int. J. Environ. Res. Public Health 15, 1382. https://doi.org/10.3390/ijerph15071382

Yang, Y.H., Ho, P.S., Lu, H.M., Huang, I.Y., Chen, C.H. (2010). Comparing dose-response measurements of oral habits on oral leukoplakia and oral submucous fibrosis from a community screening program. J. Oral Pathol. Med. 39, 306-312. https://doi.org/10.1111/j.1 600-0714.2009.00820.x 
Yen, A.M., Chen, S.C., Chen, T.H. (2007). Dose-response relationships of oral habits associated with the risk of oral pre-malignant lesions among men who chew betel quid. Oral Oncol. 43, 634-638. https://doi.org/10.1016/j.oraloncology.2006.05.001

Yen, A.M., Chen, S.C., Chang, S.H., Chen, T.H. (2008a). The effect of betel quid and cigarette on multistate progression of oral pre-malignancy. J. Oral Pathol. Med. 37, 417-422. https://doi.org/10.1111/j.1600-0714.2008.00652.x

Yen, A.M., Chen, S.L., Chiu, S.Y., Chen, H.H. (2011). Association between metabolic syndrome and oral pre-malignancy: A community- and population-based study (KCIS No. 28). Oral Oncol. 47, 625-630. https://doi.org/10.1016/j.oraloncology.2011.04.011

Yen, T.T., Lin, W.D., Wang, C.P., Wang, C.C., Liu, S.A. (2008b). The association of smoking, alcoholic consumption, betel quid chewing and oral cavity cancer: A cohort study. Eur. Arch. Otorhinolaryngol. 265, 1403-1407. https://doi.org/10.1007/s00405-008-0659-z

Yuan, T.H., Lian, I., Tsai, K.Y., Chang, T.K., Chiang, C.T., Su, C.C., Hwang, Y.H. (2011). Possible association between nickel and chromium and oral cancer: A case-control study in central Taiwan. Sci. Total Environ. 409, 1046-1052. https://doi.org/10.1016/j.scitotenv.2010.11.038

Znaor, A., Brennan, P., Gajalakshmi, V., Mathew, A., Shanta, V., Varghese, C., Boffetta, P. (2003). Independent and combined effects of tobacco smoking, chewing and alcohol drinking on the risk of oral, pharyngeal and esophageal cancers in Indian men. Int. J. Cancer 105, 681-686. https://doi.org/10.1002/ijc.11114 